\title{
Ultrasonographic Evaluation of Uterine Scar Niche before and after Laparoscopic Surgical Repair: A Case Report
}

\author{
Olivier Drouin, $\mathrm{MD}^{1} \quad$ Tessa Bergeron, $\mathrm{MD}^{1} \quad$ Ariane Beaudry, $\mathrm{MD}^{1} \quad$ Suzanne Demers, MD ${ }^{1}$ \\ Stéphanie Roberge, $\mathrm{MSc}^{2}$ Emmanuel Bujold, MD, MSc, FRCSC ${ }^{1,2}$
}

${ }^{1}$ Department of Obstetrics and Gynecology, Faculty of Medicine, Université Laval, Quebec, Canada

2 Department of Social and Preventive Medicine, Faculty of Medicine, Université Laval, Quebec, Canada

\begin{abstract}
Address for correspondence Emmanuel Bujold, MD, MSc, FRCSC, Department of Obstetrics and Gynecology, Faculty of Medicine, Université Laval, 2705 Boulevard Laurier, Québec, Canada G1V 4G2 (e-mail: emmanuel.bujold@crchul.ulaval.ca).
\end{abstract}

Am J Perinatol Rep 2014;4:e65-e68.

\begin{abstract}
Keywords

- cesarean

- laparoscopic repair

- scar defect

- hysterosonography

Context Uterine scar defects or scar niche are relatively common after cesarean delivery. An association has been observed between the severity of scar defect, also known as isthmocele, some gynecologic symptoms, and the risk of uterine scar dehiscence at the next delivery. It has been suggested that surgical repair of scar defect could improve the gynecological symptoms, but it remains unclear whether such surgery mends the uterine scar itself.

Case Report We report the case of a woman with uterine scar defect in whom laparoscopic repair significantly improved the gynecological symptoms without affecting the uterine scar, evaluated by hysterosonography.

Conclusion This case highlights the significant dearth of knowledge surrounding the diagnosis, consequences, and benefits of surgical repair of uterine scar defect after cesarean.
\end{abstract}

The proportion of cesareans has been increasing for several decades, reaching more than $30 \%$ in several countries. ${ }^{1}$ Cesarean allows safe deliveries in several conditions, but the scarred uterus has been associated with long-term adverse outcomes, including dysmenorrhea, intermenstrual bleeding, infertility, and uterine rupture in future pregnancies. $^{2}$

Uterine scar imaging with ultrasound and hysterosonography has gained popularity in the last decade. ${ }^{3-5}$ The severity of scar defect, also known as isthmocele, has been linked with gynecological symptoms and with the risk of uterine scar dehiscence or uterine rupture at delivery. ${ }^{2,3,6-8}$ While few studies have looked at risk factors for the presence and severity of uterine scar defect, interest in its treatment is growing. ${ }^{9-11}$

Several authors have reported improvement of gynecological symptoms after surgical repair of such scar defects. ${ }^{11-13}$

received

March 7, 2014

accepted after revision

March 24, 2014

published online

May 28, 2014
However, we are not aware of any comparative studies that evaluated the risks and benefits of such repair, and it remains unclear whether surgical procedures improve the scar itself or not. We report the case of a woman with uterine scar defect who underwent laparoscopic repair with hysterosonography performed before and after the procedure.

\section{Case Report}

A 38-year-old woman, gravida 1 para 1, was referred to our clinic for uterine scar evaluation. She had a cesarean, at term 6 years, earlier for maternal indication (prior lumbar traumatism). The caesarean was done in the latent phase of labor, and the hysterotomy was closed with a first locked layer followed by an imbricating second layer. A B-lynch procedure was performed to control postpartum hemorrhage secondary to uterine atonia. Three years later, the patient underwent
Copyright $\odot 2014$ by Thieme Medical Publishers, Inc., 333 Seventh Avenue, New York, NY 10001, USA. Tel: +1(212) 584-4662.
License terms

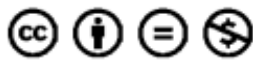

10.1055/s-0034-1376187. ISSN 2157-6998. 


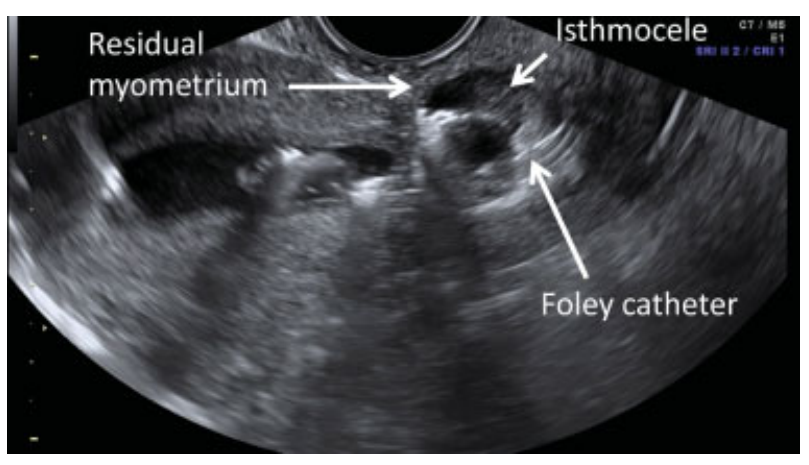

Fig. 1 Hysterosonographic picture of the isthmocele before surgery showing a $2.3 \mathrm{~mm}$ residual myometrium.

medical evaluation for secondary infertility, including a hysterosonography that revealed a uterine scar defect with residual myometrium thickness of $2.3 \mathrm{~mm}$ (- Fig. 1). At that time, she was complaining of dysmenorrhea. Laparoscopic repair of the scar was decided. The surgery was undertaken as described after reflection of the bladder flap, the low uterine segment section, including the defect, was removed, and the hysterotomy was closed with three, single synthetic absorbable sutures. ${ }^{14}$ No complication from surgery or from the postoperative period was encountered. The patient reported complete resolution of her gynecological symptoms, but the infertility problem remained. A second hysterosonography was performed 23 months after surgery and revealed the persistence of the uterine scar defect with residual myometrium thickness of $2.9 \mathrm{~mm}$ (-Fig. 2).

\section{Discussion}

This case report indicates that laparoscopic repair of uterine scar defect can resolve gynecological symptoms without significant improvement of the uterine scar defect. We suggest that the disease mechanisms of dysmenorrhea and postmenstrual bleeding related to a previous cesarean are independent of uterine scar defect severity. We hypothesize that inclusion of endometrial tissue into the scar at the time of caesarean causes subsequent gynecological symptoms. Removal of such tissue by hysteroscopy or laparoscopy could potentially ameliorate the symptoms without changing the scar defect aspect and improving residual myometrium thickness. Finally, it remains unclear whether or not vaginal delivery is safe after such a procedure and

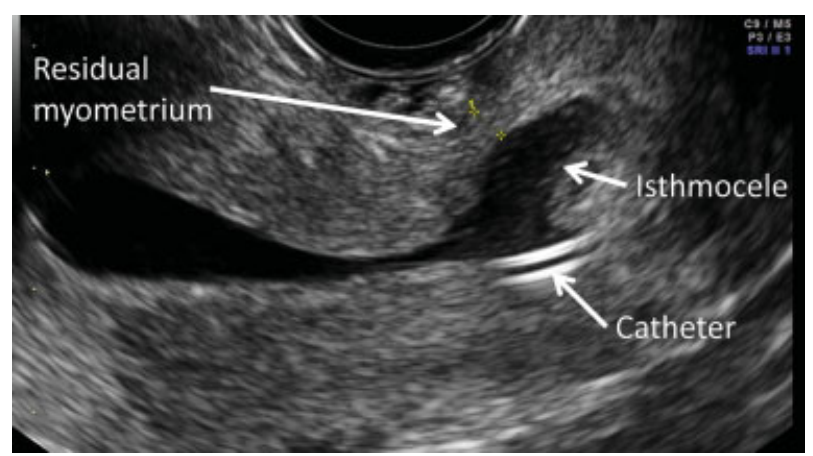

Fig. 2 Hysterosonographic picture of the isthmocele 23 months after surgery showing a $2.9 \mathrm{~mm}$ residual myometrium. whether the risk of uterine rupture is increased or not. While Marotta et $\mathrm{al}^{9}$ recommend cesarean delivery in future pregnancies, Jeremy et $\mathrm{al}^{11}$ reported vaginal delivery without complications after this type of surgery.

Several case series of hysteroscopic and laparoscopic repair of uterine scar defects have been published, but very few of them undertook imaging and evaluation of the scar defect appearance after the surgical procedure. Marotta et al reported on 13 women who underwent magnetic resonance imaging 3 months after laparoscopic repair of isthmocele with significant improvement of residual myometrium thickness. However, complete scar healing takes at least 6 to 9 months, and it is not unusual to see an increase of low uterine segment thickness at the site of the scar in the following weeks after surgery. ${ }^{15}$ Moreover, it is quite surprising that $100 \%$ of women presented such improvement of residual myometrium thickness, the thinnest being $8.3 \mathrm{~mm}$ after repair. It is possible that closure of hysterotomy, with three single stitches in the nonpregnant state, leads to better healing than continuous layers at the time of cesarean. We suggest that magnetic resonance imaging is not the best tool to evaluate uterine scar defect in the low uterine segment.

This case and our literature review highlight the significant lack of knowledge surrounding the diagnosis, consequences, and benefits of surgical repair of uterine scar defect. We believe that in the absence of appropriate comparative studies, surgical repair of scar defect should be reserved for randomized trials. Such trials should include long-term follow-up and uterine scar evaluation with ultrasound and/ or hysterosonography in nonpregnant women and ultrasound during pregnancy. Moreover, additional studies evaluating modifiable risk factors of uterine scar defect, such as type of uterine closure at cesarean, should be considered.

\section{Funding}

Emmanuel Bujold holds a Clinician Scientist Award; Stéphanie Roberge and Suzanne Demers, a PhD and an MSc Study Award from Fonds de recherche du Québec - Santé. This study was supported by the Jeanne and Jean-Louis Lévesque Perinatal Research Chair at Université Laval, Quebec, QC, Canada.

\section{Disclosure of Interests}

None of the authors has disclosed any potential conflicts of interest.

\section{References}

1 National Institutes of Health state-of-the-science conference statement: Cesarean delivery on maternal request March 27-29, 2006. Obstet Gynecol 2006;107(6):1386-1397

2 Tower AM, Frishman GN. Cesarean scar defects: an underrecognized cause of abnormal uterine bleeding and other gynecologic complications. J Minim Invasive Gynecol 2013;20(5):562-572

3 Roberge S, Boutin A, Chaillet N, et al. Systematic review of cesarean scar assessment in the nonpregnant state: imaging techniques and uterine scar defect. Am J Perinatol 2012;29(6):465-471

4 Jastrow N, Chaillet N, Roberge S, Morency AM, Lacasse Y, Bujold E. Sonographic lower uterine segment thickness and risk of uterine 
scar defect: a systematic review. J Obstet Gynaecol Can 2010;32(4): 321-327

5 Bujold E, Jastrow N, Simoneau J, Brunet S, Gauthier RJ. Prediction of complete uterine rupture by sonographic evaluation of the lower uterine segment. Am J Obstet Gynecol 2009;201(3):e1-e6

6 Wang CB, Chiu WW, Lee CY, Sun YL, Lin YH, Tseng CJ. Cesarean scar defect: correlation between Cesarean section number, defect size, clinical symptoms and uterine position. Ultrasound Obstet Gynecol 2009;34(1):85-89

7 Vikhareva Osser O, Valentin L. Clinical importance of appearance of cesarean hysterotomy scar at transvaginal ultrasonography in nonpregnant women. Obstet Gynecol 2011;117(3):525-532

8 Waniorek A. Hysterography after cesarean section. With special reference to the effect of subsequent delivery on the hysterographic findings. Am J Obstet Gynecol 1966;94(1):42-49

9 Marotta ML, Donnez J, Squifflet J, Jadoul P, Darii N, Donnez O. Laparoscopic repair of post-cesarean section uterine scar defects diagnosed in nonpregnant women. J Minim Invasive Gynecol 2013;20(3):386-391
10 La Rosa MF, McCarthy S, Richter C, Azodi M. Robotic repair of uterine dehiscence. JSLS 2013;17(1):156-160

11 Jeremy B, Bonneau C, Guillo E, et al. Uterine ishtmique transmural hernia: results of its repair on symptoms and fertility [in French]. Gynecol Obstet Fertil 2013;41(10):588-596

12 Fabres C, Arriagada P, Fernández C, Mackenna A, Zegers F, Fernández E. Surgical treatment and follow-up of women with intermenstrual bleeding due to cesarean section scar defect. J Minim Invasive Gynecol 2005;12(1):25-28

13 Klemm P, Koehler C, Mangler M, Schneider U, Schneider A. Laparoscopic and vaginal repair of uterine scar dehiscence following cesarean section as detected by ultrasound. J Perinat Med 2005;33(4):324-331

14 Donnez O, Jadoul P, Squifflet J, Donnez J. Laparoscopic repair of wide and deep uterine scar dehiscence after cesarean section. Fertil Steril 2008;89(4):974-980

15 Dicle O, Küçükler C, Pirnar T, Erata Y, Posaci C. Magnetic resonance imaging evaluation of incision healing after cesarean sections. Eur Radiol 1997;7(1):31-34 